\begin{tabular}{|c|l|}
\hline Title & $\begin{array}{l}\text { An organocatalytic ring-opening polymerization approach to highly alternating copolymers of lactic acid and glycolic } \\
\text { acid }\end{array}$ \\
\hline Author(s) & $\begin{array}{l}\text { Takojima, Kaoru; Makino, Hiroshi; Saito, Tatsuya; Y amamoto, Takuya; Tajima, Kenji; Isono, Takuya; Satoh, } \\
\text { Toshifumi }\end{array}$ \\
\hline Citation & $\begin{array}{l}\text { Polymer chemistry, 11(39), 6365-6373 } \\
\text { https://doi.org/10.1039/d0py01082k }\end{array}$ \\
\hline Issue Date & 2020-10-21 \\
\hline Doc URL & http://hdl.handle.net/2115/82995 \\
\hline Type & article (author version) \\
\hline File Information & main text_rev2 (Isono).pdf \\
\hline
\end{tabular}

Instructions for use 


\section{Organocatalytic Ring-opening Polymerization Approach to Highly Alternating Copolymers of Lactic Acid and Glycolic Acid}

Kaoru Takojima, ${ }^{\dagger}$ Hiroshi Makino, ${ }^{\ddagger}$ Tatsuya Saito,${ }^{\dagger}$ Takuya Yamamoto, ${ }^{\S}$ Kenji

Tajima, ${ }^{\S}$ Takuya Isono, ${ }^{\S, *}$ Toshifumi Satoh ${ }^{\S, *}$

${ }^{\dagger}$ Graduate School of Chemical Sciences and Engineering, Hokkaido University, Sapporo 060-8628, Japan

\$ School of Engineering, Hokkaido University, Sapporo 060-8628, Japan

$\S$ Division of Applied Chemistry, Faculty of Engineering, Hokkaido University, Sapporo 060-8628, Japan

*To whom corresponding should be addressed: isono.t@eng.hokudai.ac.jp (T. Isono) and satoh@eng.hokudai.ac.jp (T. Satoh) 


\section{Abstract}

The alternating copolymer of lactic acid and glycolic acid (PLGA) is a highly promising next generation biodegradable material for biomedical and pharmaceutical applications due to its uniform degradation behaviors in addition to its ability to form stereocomplexes. However, versatile synthetic methods toward the narrowly dispersed alternating PLGAs with controlled molecular weights and desired end functionalities have been largely unexplored. Herein, we report the organocatalytic regioselective ring-opening polymerization (ROP) of optically active methylglycolides (L- and DMGs) to produce highly alternating PLGAs. The ROP of L-MG using a phosphazene base $\mathrm{P}_{2-t}$ $\mathrm{Bu} /$ alcohol system in $\mathrm{THF}$ at $-78^{\circ} \mathrm{C}$ achieved the highest regioselectivity $(P=0.95)$ as well at a good control over the molecular weight $\left(M_{\mathrm{n}}=6.6-15.6 \mathrm{~g} \mathrm{~mol}^{-1}\right)$, with a relatively narrow dispersity $(\bigoplus=$ 1.21 - 1.29). Furthermore, alternating PLGAs diol as well as azido-, ethynyl-, and poly(ethylene glycol) monomethyl ether-end-functionalized alternating PLGAs were successfully obtained by employing the corresponding functional alcohol initiators. An enantiomeric 1:1 blend of PLGAs prepared from L- and D-MGs formed a stereocomplex with a crystallinity and melting point comparable to the reported data for the stereocomplex from the perfectly alternating PLGAs produced via a polycondensation approach, which implies the high degree of the alternating sequence of the obtained copolymers. 


\section{Introduction}

The poly(lactic-co-glycolic acid)s (PLGAs) constitute a family of aliphatic polyesters composed of lactic acid and glycolic acid units, and they are one of the most popular synthetic polymers for biomedical applications, such as release devices for drug delivery systems ${ }^{1-3}$ and tissue engineering. ${ }^{4-6}$ This is partly due to the fact that they are approved by the Food and Drug Administration (FDA) because of their excellent biodegradability and biocompatibility. The majority of PLGAs are synthesized either by the direct polycondensation of lactic acid and glycolic acid or by the ring-opening copolymerization of lactide (LA) and glycolide (GA), ${ }^{7}$ and therefore the monomer sequence of the resulting copolymers is limited to random or blocky. As a result, the effect of the monomer sequence on the material properties has been largely unexplored, with the exception of a few studies. For example, Meyer and coworkers carefully investigated the impact of the monomer sequence on the hydrolytic degradation behavior by employing a series of PLGAs with defined monomer sequences. ${ }^{8,9}$ Interestingly, the molecular weight of alternating PLGA was found to linearly decrease upon the hydrolytic degradation. In contrast, the random copolymer counterpart rapidly degraded with an exponential decrease in the molecular weight. Another interesting aspect of alternating PLGA was discovered by Tsuji and coworkers, who found that a 1:1 blend of alternating poly(L-lactic-co-glycolic acid) (PLLGA) and poly(D-lactic-co-glycolic acid) (PDLGA) formed a stereocomplex (SC) with a high melting point $\left(T_{\mathrm{m}}\right)$ of $\sim 188^{\circ} \mathrm{C},{ }^{10}$ which may exhibit improved 
thermal/mechanical properties and expand the scope of application of such materials.

Currently, the segmer assembly polymerization approach, which involves the polycondensation of a pre-organized monomer with a tailor-made microstructure, is the only feasible way to synthesize the perfectly alternating PLGA (Figure 1a). ${ }^{11-14}$ However, polymerization control remains a challenge when employing the polycondensation approach. In contrast, ring-opening polymerization (ROP) is the most powerful tool to synthesize polylactides (PLAs) and conventional PLGAs, since this approach gives well-defined (co)polymers with controllable molecular weights, narrow dispersities, and the desired end functionalities. Thus, to incorporate the advantages of the ROP approach while enabling monomer sequence control, the regioselective ROP of methylglycolide (MG), a cyclic cross-dimer of lactic acid and glycolic acid, could be ideal, since the repetitive ringopening from only one side (either the lactyl or glycolyl side) would give the alternating PLGA. However, this regioselective ROP of MG has been largely unexplored, and, indeed, only two successful examples have been reported to date, in which organometallic catalysts, such as stannous octanoate $\left(\mathrm{Sn}(\mathrm{Oct})_{2}\right)^{15}$ and the bimetallic $(\mathrm{Al} / \mathrm{Zn}) \mu$-oxo alkoxide, ${ }^{16}$ were employed for the ROP of rac-MG to produce atactic PLGAs (Figure 1b). Unfortunately, the reported regioselectivities $(P$ values; probability of the ring-opening from one side) remained insufficient $(\sim 0.85)$ to achieve a desirable length of the alternating sequence. Moreover, no further advance in this direction has been made so far. 
As an alternative to the organometal-catalyzed ROP, considerable attention has recently been focused on organocatalytic polymerization systems, especially in the ROP of cyclic esters to give biodegradable and biocompatible polymers. This approach is particularly advantageous for the following reasons: (1) the organocatalytic approach gives a well-defined polymer under mild conditions; (2) the organocatalysts showing different activation modes have been developed, expanding the scope of applicable monomers; (3) tuning of the catalyst structure is relatively easy, rending it possible to control the reactivity and selectivity; and (4) undesirable heavy metal contamination can be avoided. ${ }^{17-19}$ However, regio- and stereoselective ROPs using organocatalysts are challenging compared to the organometallic approach. Indeed, only a few reports exist into regio20 and stereoselective ${ }^{21-29}$ ROP reactions using organocatalysts, albeit there is still room for improvement in terms of their selectivities. Therefore, the development of organocatalytic regio- and stereoselective ROPs is a significant challenge in both organic and polymer chemistry fields. Considering the potential biomedical and pharmaceutical applications, establishing a metal-free pathway for alternating PLGA via the regioselective ROP is of particular importance. Herein, we explore an efficient organocatalytic regioselective ROP of optically active MGs (L- and D-MGs) to produce highly alternating PLGAs with predictable molecular weights, narrow dispersities, and desired functional end groups (Figure 1c). This is the first example of the ROP of optically active MGs to produce stereoregular alternating PLAGs. Through the screening of various organocatalysts 
including acidic and basic ones, the phosphazene base $\mathrm{P}_{2}-t-\mathrm{Bu}$ was found to be the best catalyst for the highly regioselective ROP of L- and D-MGs. The NMR analysis revealed the high degree of the alternating sequence in the resulting copolymers. Further, an enantiomeric 1:1 blend of PLGAs prepared from L- and D-MGs with this catalyst formed a stereocomplex with a crystallinity and melting point comparable to the stereocomplex reported by Tsuji, ${ }^{10}$ which formally confirmed the high degree of the alternating sequence. 
(a) Previous work: Segmer assembly polymerization<smiles>CC(OC(=O)CO)C(=O)OCC(=O)O</smiles>

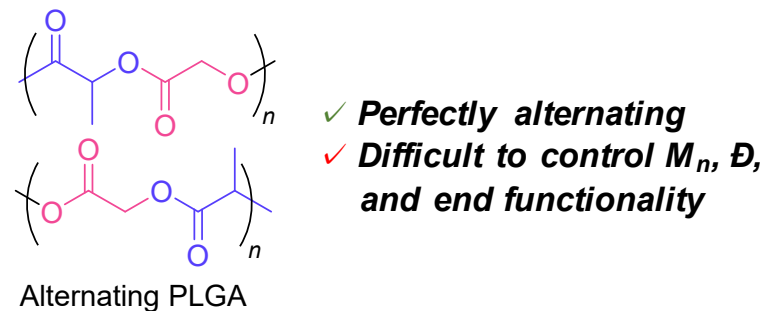

(b) Previous work: Regioselective ROP using organometallic catalysts<smiles>CC1OCC(=O)OC1C</smiles>

$\mathrm{Sn}(\mathrm{Oct})_{2}$ or bimetallic (Al/Zn) $\mu$-oxo alkoxide $\mathrm{R}-\mathrm{OH}$<smiles>[R20]C(C)C(=O)OCC(=O)C(C)OC(C)C</smiles>

Easy to control $M_{n}, \boldsymbol{\oplus}$, and end functionality Less regioselectivity

rac-MG

(c) This work: Regioselective ROP using organocatalysts<smiles>CC(C)C(=O)OCC(=O)O</smiles><smiles>COC(=O)COC(=O)[C@H](C)O</smiles>

Organocatalyst R-OH R-OH<smiles>[R]OC(C)(C)C(=O)C(C)OC(=O)COC(C)(C)C</smiles><smiles></smiles>
Metal free

Easy to control $M_{n}, \emptyset$, and end functionality

PDLGA

$P \sim 0.95\left(\mathbf{P}_{2}-t-B u\right)$

Organocatalyst

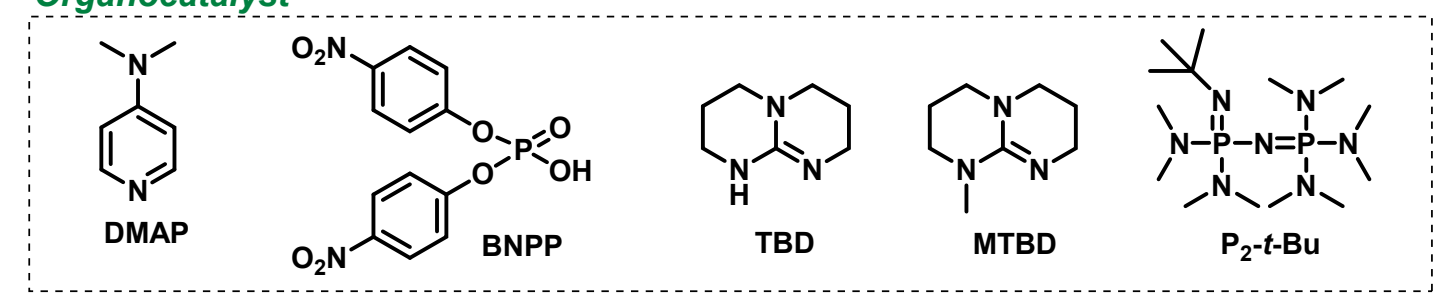

Figure 1. Synthetic strategies for alternating PLGA. (a) Segmer assembly polymerization approach. (b) Regioselective ROP of rac-MG using an organometallic catalyst to produce atactic alternating PLGA. (c) Regioselective ROP of L- and D-MGs using organocatalysts to produce isotactic alternating PLGAs. 


\section{Results and Discussion}

Our initial effort was directed toward establishing a suitable method for evaluating the regioselectivity of the ROP using the obtained copolymer to allow accurate screening of the catalyst and polymerization conditions for the production of PLGA with a higher alternating sequence. $N, N$ Dimethyl-4-aminopyridine (DMAP) was selected as the catalyst for the ROP of L-MG, as it had been successfully applied in the ROP of LA. ${ }^{30,31}$ The DMAP-catalyzed ROP was carried out in the presence of 3-phenyl-1-propanol (PPA) as the initiator, with an initial [L-MG $]_{0} /[\mathrm{PPA}]_{0} /[\mathrm{DMAP}]$ ratio of 50/1/5 at $30{ }^{\circ} \mathrm{C}$ in $\mathrm{CH}_{2} \mathrm{Cl}_{2}\left([\mathrm{~L}-\mathrm{MG}]_{0}=1.0 \mathrm{M}\right)$ for $18 \mathrm{~h}$, which yielded a PLLGA $\left(M_{\mathrm{n}, \mathrm{NMR}}=5.9 \mathrm{~kg} \mathrm{~mol}^{-1}, Ð\right.$ $=1.18$, Figure S1a) with a monomer conversion of $89 \%$ (run 1 in Table 1). The MALDI-TOF MS spectrum for the obtained PLLGA exhibited five series of periodic peaks, in which the main peaks (denoted by filled circle) can be assigned to the copolymers initiated from PPA (Figure S2). Importantly, all the series of peaks exhibited a regular interval of $130.0 \mathrm{Da}$, corresponding to the lactyl-glycolyl or glycolyl-lactyl repeating unit, demonstrating the absence of random scrambling in the main chain ester bonds. The other minor peaks were assigned to the copolymer initiated from $\mathrm{H}_{2} \mathrm{O}$ (denoted by open circle), PPA-initiated copolymers with an extra glycolyl (filled square) or lactyl unit (open square), and cyclic copolymer (x). Given the small population of these minor peaks, the side reactions involving transesterification and backbiting are suppressed. The ${ }^{13} \mathrm{C}$ NMR spectrum revealed that all carbon signals were split into multiple peaks (lower panel, Figure 2a). The ${ }^{1} \mathrm{H}$ NMR 
signals for the main chain methine and methylene also showed complicated splitting patterns (lower panel, Figure 2b). According to the previous literatures, ${ }^{12,13}$ the ${ }^{1} \mathrm{H}$ NMR main chain methylene signal for the perfectly alternating PLLGA appears as a pair of doublets (4.86 and $4.63 \mathrm{ppm}$ ). The appearance of additional peaks in main chain methylene region reflects the non-alternating sequences, such as LLG and LGG, where the L and G represent the lactyl and glycolyl units, respectively. These NMR data implies the coexistence of several different monomer sequences in the copolymer as well as a low regioselectivity for the ROP. 
Table 1. ROP of MGs using various organocatalysts ${ }^{a}$

\begin{tabular}{|c|c|c|c|c|c|c|c|c|c|c|c|c|}
\hline run & cat. & monomer & {$[\mathrm{MG}]_{0} /[\mathrm{PPA}]_{0} /[\mathrm{cat} .]_{0}$} & solvent & $\begin{array}{l}\text { temp. } \\
\left({ }^{\circ} \mathrm{C}\right)\end{array}$ & time & $\begin{array}{c}\text { conv. } \\
(\%)\end{array}$ & $\begin{array}{c}M_{\mathrm{n}, \text { th. }}{ }^{c} \\
\left(\mathrm{~kg} \mathrm{~mol}^{-1}\right)\end{array}$ & $\begin{array}{c}M_{\mathrm{n}, \mathrm{NMR}}{ }^{b} \\
\left(\mathrm{~kg} \mathrm{~mol}^{-1}\right)\end{array}$ & $\begin{array}{c}M_{\mathrm{n}, \mathrm{SEC}}{ }^{d} \\
\left(\mathrm{~kg} \mathrm{~mol}^{-1}\right)\end{array}$ & $\bigoplus^{d}$ & $P^{e}$ \\
\hline 1 & $\operatorname{DMAP}^{f}$ & L-MG & $50 / 1 / 5$ & $\mathrm{CH}_{2} \mathrm{Cl}_{2}$ & 30 & $18 \mathrm{~h}$ & 89 & 5.9 & 5.9 & 8.6 & 1.18 & 0.69 \\
\hline 2 & $\operatorname{DMAP}^{f}$ & D-MG & $50 / 1 / 5$ & $\mathrm{CH}_{2} \mathrm{Cl}_{2}$ & 30 & $18 \mathrm{~h}$ & 76 & 5.1 & 5.4 & 6.8 & 1.12 & 0.71 \\
\hline 3 & $\mathrm{BNPP}^{g}$ & L-MG & $50 / 1 / 2$ & toluene & 60 & $72 \mathrm{~h}$ & 62 & 4.2 & 3.5 & 3.5 & 1.17 & 0.50 \\
\hline 4 & TBD & L-MG & $50 / 1 / 0.2$ & $\mathrm{CH}_{2} \mathrm{Cl}_{2}$ & -78 & $1 \mathrm{~min}$ & 97 & 6.4 & 19.3 & 18.2 & 1.22 & 0.89 \\
\hline 5 & MTBD & L-MG & $50 / 1 / 0.2$ & $\mathrm{CH}_{2} \mathrm{Cl}_{2}$ & -78 & $20 \mathrm{~min}$ & 80 & 5.3 & 10.9 & 12.9 & 1.34 & 0.96 \\
\hline 6 & $\mathrm{P}_{2}-t-\mathrm{Bu}$ & L-MG & $50 / 1 / 0.2$ & THF & -78 & $1 \mathrm{~min}$ & 89 & 5.9 & 6.6 & 8.4 & 1.21 & 0.95 \\
\hline 7 & $\mathrm{P}_{2}-t-\mathrm{Bu}$ & L-MG & $50 / 1 / 0.5$ & $\mathrm{CH}_{2} \mathrm{Cl}_{2}$ & -78 & $3 \mathrm{~min}$ & $>99$ & 6.6 & 9.4 & 14.0 & 1.30 & 0.94 \\
\hline 8 & $\mathrm{P}_{2}-t-\mathrm{Bu}$ & D-MG & $50 / 1 / 0.2$ & THF & -78 & $1 \mathrm{~min}$ & $>99$ & 6.6 & 7.0 & 10.0 & 1.36 & 0.95 \\
\hline 9 & $\mathrm{P}_{2}-t-\mathrm{Bu}$ & L-MG & $100 / 1 / 0.4$ & THF & -78 & $2 \min$ & 72 & 9.5 & 9.7 & 10.9 & 1.22 & 0.89 \\
\hline 10 & $\mathrm{P}_{2}-t-\mathrm{Bu}$ & L-MG & $200 / 1 / 0.8$ & THF & -78 & $25 \mathrm{~min}$ & 55 & 14.5 & 15.6 & 12.6 & 1.29 & 0.91 \\
\hline
\end{tabular}

${ }^{a}$ Polymerization conditions: Ar atmosphere; initiator, PPA; $[\mathrm{MG}]_{0}=0.080 \mathrm{M} .{ }^{b}$ Determined by ${ }^{\mathrm{l}} \mathrm{H}$ NMR analysis of the obtained polymer in CDCl 3 . ${ }^{c}$ Calculated using $[\mathrm{MG}]_{0} /[\mathrm{PPA}]_{0} \times$ conv. $\times(\mathrm{M} . \mathrm{W}$. of MG $)+\left(\mathrm{M} . \mathrm{W}\right.$. of PPA). ${ }^{d}$ Determined by the SEC analysis of the obtained polymer in THF with a PSt standard. ${ }^{e}$ Probability of one side cleavage determined by the ${ }^{1} \mathrm{H}$ NMR analysis. ${ }^{f}[\mathrm{MG}]_{0}=1.0 \mathrm{M} .{ }^{g}[\mathrm{MG}]_{0}=3.0 \mathrm{M}$. 
(a) ${ }^{13} \mathrm{C}$ NMR

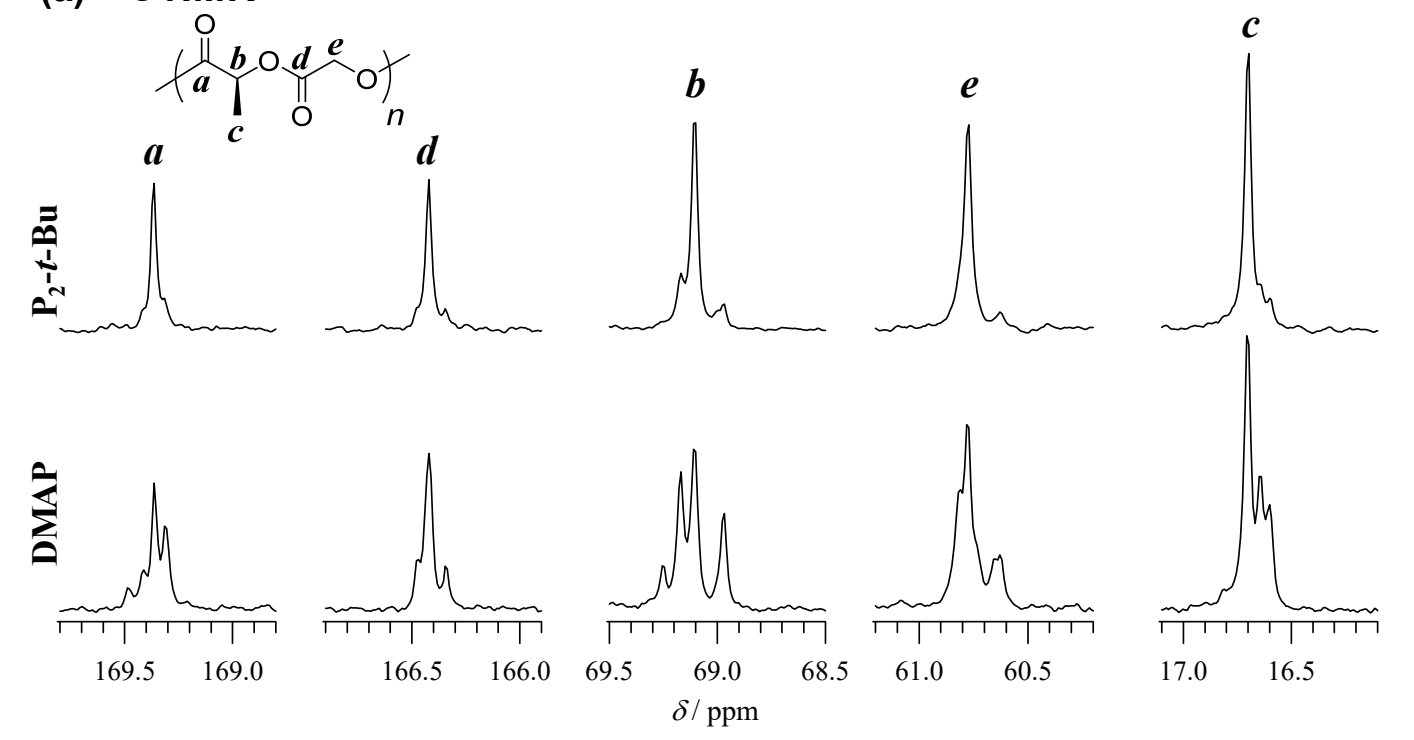

(b) ${ }^{1} \mathrm{H}$ NMR

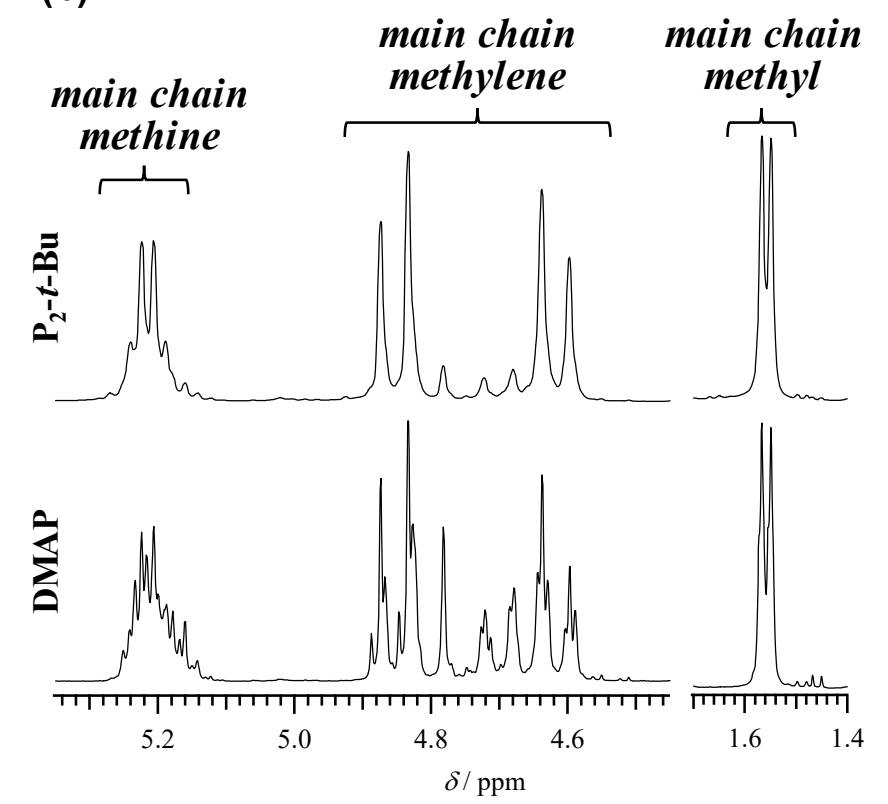

(c) Homodecoupling ${ }^{1} \mathrm{H}$ NMR

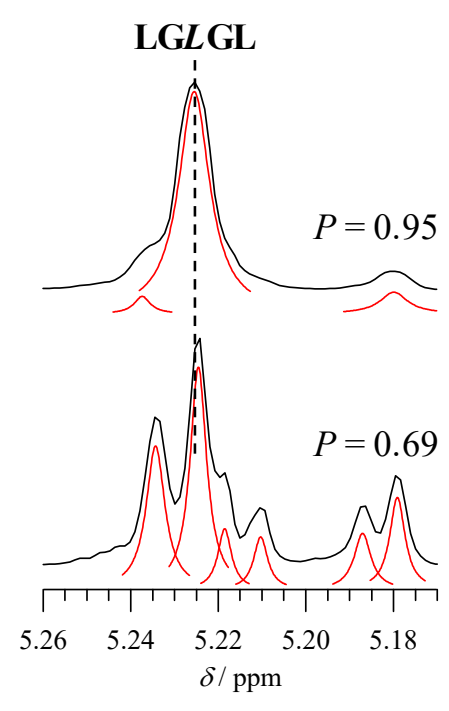

Figure 2. NMR analysis of the PLLGAs obtained using DMAP (run 1, Table 1, lower) and $\mathrm{P}_{2}-t$-Bu (run 6, Table 1, upper) catalysts. (a) ${ }^{13} \mathrm{C}$ NMR spectra of the obtained PLLGAs (in $\mathrm{CDCl}_{3} ; 100 \mathrm{MHz}$ ). (b) Expanded ${ }^{1} \mathrm{H}$ NMR spectra for the main chain methine, methylene, and methyl regions (in $\mathrm{CDCl}_{3}$; $400 \mathrm{MHz}$ ). (c) Homodecoupling ${ }^{1} \mathrm{H}$ NMR spectra for the methine region of the obtained PLLGAs (in $\mathrm{CDCl}_{3} ; 400 \mathrm{MHz}$ ). The red curves represent the result of peak deconvolution.

To quantify the regioselectivity of the ROP, we attempted to estimate the $P$ value based on the homodecoupling ${ }^{1} \mathrm{H}$ NMR spectrum for the methine region of the obtained copolymer (lower 
panel, Figure 2c). Figure S3a depicts the possible hexamer sequences generated through three consecutive ring-opening reactions from the lactyl and glycolyl sides, respectively. Here, we hypothesize that $P$ is independent of the propagating chain-end structure. Under this assumption, the possibility to generate each hexamer sequence can be simply expressed as a function of $P$ (Figure S3a). Thus, the $P$ can be estimated from the area ratio of the NMR peak relating to each hexamer sequence, although we could not determine which ester bond was preferentially cleaved at this moment. In the homodecoupling ${ }^{1} \mathrm{H}$ NMR spectrum (Figure 2c), the signals around 5.3 - 5.2 ppm are assignable to the lactyl methin protons of the lactyl-centered pentads. Among them, the largest peak at $5.225 \mathrm{ppm}$ is unambiguously assigned to the lactyl methine proton of the alternating LG sequence (= LGLGL) according to the reported literature, ${ }^{12}$ which represents the LGLGLG and GLGLGL hexamer sequences generated through three consecutive ring-opening reactions of L-MG from the lactyl and glycolyl cleavage, respectively. Here, the peak area ratio of the LGLGL signals was determined to be 0.36 by the peak deconvolution, from which the $P$ value was estimated to be 0.69 based on the relationship of [peak area ratio of $\mathrm{LGLGL}]=P^{3}+(1-P)^{3}$ (see ESI for more details). To further verify the $P$ value, we then investigated the ${ }^{13} \mathrm{C}$ NMR spectrum (Figure S4). By taking the largest peak at $69.11 \mathrm{ppm}$ due to the lactyl methine carbon of the L-centered pentad of LGLGL, ${ }^{12}$ the $P$ value can be estimated to be 0.72 , which reasonably agree with that determined by the ${ }^{1} \mathrm{H}$ NMR analysis. Note that ${ }^{13} \mathrm{C}$ NMR spectrum is generally not utilized for the calculation of peak area integration ratio. However, in this study, the comparison is conducted among the signals due the same 
type of carbons, which renders the $P$ value calculation reasonable.

By applying the above-discussed polymerization condition to D-MG, a PDLGA, the D-form counterpart of PLLGA, with the $M_{\mathrm{n}, \mathrm{NMR}}$ of $5.4 \mathrm{~kg} \mathrm{~mol}^{-1}(Ð=1.12)$ was obtained (run 2 in Table 1). The ${ }^{1} \mathrm{H}$ NMR analysis revealed the $P$ value of 0.71 (Figure S5), which is comparable to the case of the L-MG polymerization (run 1 in Table 1).

To explore better organocatalyst for the regioselective ROP, bis(4-nitrophenyl) phosphate (BNPP) was then employed as an acidic catalyst (run 3 in Table 1). BNPP is known to catalyze the ROP of LA by activating both the propagating chain end and the monomer carbonyl group. ${ }^{32}$ Indeed, BNPP promoted the ROP of L-MG with an initial $[\mathrm{L}-\mathrm{MG}]_{0} /[\mathrm{PPA}]_{0} /[\mathrm{BNPP}]$ ratio of $50 / 1 / 2$ at a relatively high temperature of $60^{\circ} \mathrm{C}$ in toluene $\left([\mathrm{L}-\mathrm{MG}]_{0}=3.0 \mathrm{M}\right)$. The monomer conversion reached $62 \%$ in $72 \mathrm{~h}$, and the obtained PLLGA had a reasonable molecular weight $\left(M_{\mathrm{n}, \mathrm{NMR}}=3.5 \mathrm{~kg} \mathrm{~mol}^{-1}\right)$ with a narrow $Ð$ value of 1.17 . The homodecoupling ${ }^{1} \mathrm{H}$ NMR spectrum of the obtained PLLGA also exhibited multiply split peaks in the main chain methine region, implying lower regioselectivity. Based on the above-established method, the $P$ value was estimated to be 0.50 (Figure S6), which indicating the random distribution of the $\mathrm{L}$ and $\mathrm{G}$ units in the resulted copolymer.

We subsequently focused on basic organocatalysts, such as 1,5,7-triazabicyclo[4.4.0]dec-5ene (TBD), 7-methyl-1,5,7-triazabicyclo[4.4.0]dec-5-ene (MTBD), and the phosphazene base $\mathrm{P}_{2}-t$ $\mathrm{Bu}\left(\mathrm{P}_{2}-t-\mathrm{Bu}\right)$, which could promote the ROP even at a low temperature $\left(-78^{\circ} \mathrm{C}\right)$. When TBD was employed for the ROP with a $[\mathrm{L}-\mathrm{MG}]_{0} /[\mathrm{PPA}]_{0} /[\mathrm{TBD}]$ ratio of 50/1/0.2 in $\mathrm{CH}_{2} \mathrm{Cl}_{2}\left([\mathrm{~L}-\mathrm{MG}]_{0}=0.080\right.$ 
$\mathrm{M})$, the monomer conversion reached $97 \%$ in $1 \mathrm{~min}$. The $M_{\mathrm{n}, \mathrm{NMR}}\left(19.3 \mathrm{~kg} \mathrm{~mol}^{-1}\right)$ and $M_{\mathrm{n}, \mathrm{SEC}}(18.2 \mathrm{~kg}$ $\left.\mathrm{mol}^{-1}\right)$ of the obtained PLLGA were significantly higher than the theoretical value $\left(M_{\mathrm{n}, \text { th. }}\right)$ of $6.4 \mathrm{~kg}$ $\mathrm{mol}^{-1}$ (run 4 in Table 1), which could be due to a low initiation efficiency. Meanwhile, the homodecoupling ${ }^{1} \mathrm{H}$ NMR spectrum showed a dramatic improvement in the peak area corresponding to the LGLGL (5.223 ppm), from which the $P$ value was estimated to be 0.89 , thereby confirming the highly alternating sequence in the copolymer (Figure S7). Similarly, when using MTBD as the catalyst, a higher $P$ value of 0.96 was observed, although the molecular weight of the obtained copolymer also deviated from the $M_{\mathrm{n}, \text { th }}$ (run 5 in Table 1; Figure S8). Furthermore, when $\mathrm{P}_{2}-t$-Bu was used as the catalyst in THF, the monomer conversion reached $89 \%$ in 1 min, yielding a PLLGA with narrow $Ð$ value of 1.21 (run 6 in Table 1). Importantly, the molecular weight of this copolymer

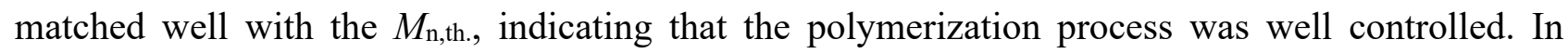
addition, the MALDI-TOF MS spectrum showed only one series of peaks corresponding to the PLLGA with the lactyl-glycolyl or glycolyl-lactyl repeating units initiated from PPA, confirming the absence of any structural error resulting from the scrambling and scission of the main chain ester bonds during ROP (Figure 3). Furthermore, in the ${ }^{13} \mathrm{C}$ NMR spectrum of the PLLGA obtained using $\mathrm{P}_{2}-t$ - $\mathrm{Bu}$ (upper panel, Figure 2a), the carbon signals were sharper than those obtained in the reaction using DMAP (lower panel, Figure 2a). The ${ }^{1} \mathrm{H}$ NMR spectrum (upper panel, Figure 2b) resembles that of the perfectly alternating PLLGA prepared by the polycondensation approach, ${ }^{12}$ which implies the high level of alternating sequence in the copolymer. The clear doublet signal due to the main chain 
methyl group suggests the high level of the isotacticity in the obtained copolymer, whereas the atactic counterpart is known to show four pairs of doublet depending on the relative stereochemistry of the neighboring lactyl units. ${ }^{12}$ Moreover, the $P$ value estimated from the homodecoupling ${ }^{1} \mathrm{H}$ NMR spectrum was 0.95 (Figures 2c and S9). The $P$ value calculated based on the analysis of the lactyl methine signal was 0.90 (Figure $\mathrm{S} 10$ ), which is comparable to the one calculated based on the ${ }^{1} \mathrm{H}$ NMR analysis. Thus, $\mathrm{P}_{2}-t-\mathrm{Bu}$ is the best catalyst to realize high level of regioselectivity with controlled polymerization properties. Note that the use of $\mathrm{CH}_{2} \mathrm{Cl}_{2}$ as the solvent, instead of THF, did not affect the $P$ value of the resulting copolymer (run 7 in Table 1; Figure S11). In addition, the highly alternating PDLGA was obtained with the $P$ value of 0.95 by applying the $\mathrm{P}_{2}-t$-Bu catalyst to D-MG (run 8 in Table 1; Figure S12). ${ }^{33}$ 
(a)

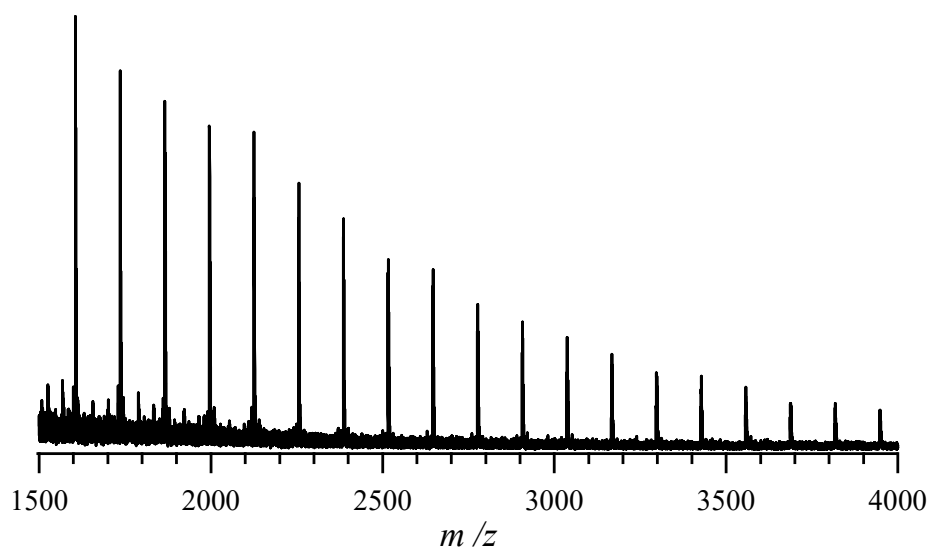

(b)

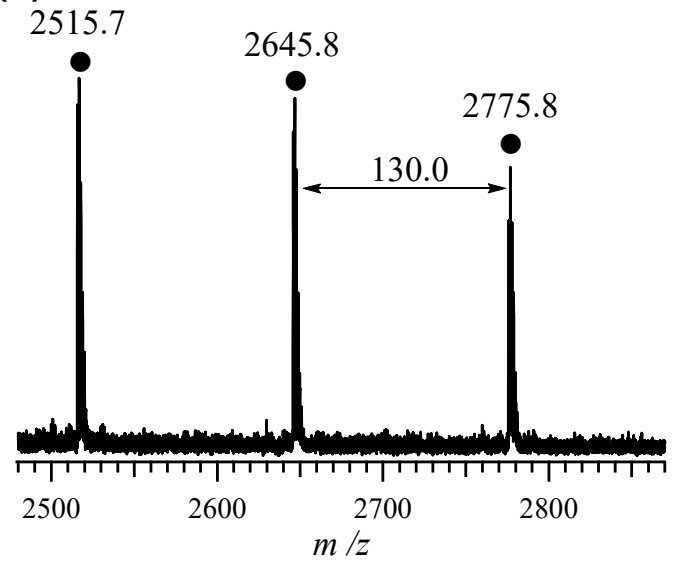

(c)

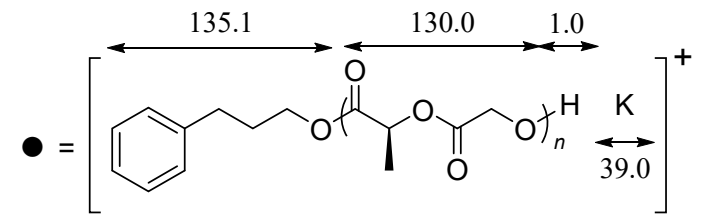

$$
\begin{aligned}
& \text { M.W. }=(\text { PPA })+(\text { Monomer unit }) \times n+\mathrm{K}^{+} \\
& \begin{array}{cc}
\hline \text { theoretical values } \\
\hline 2515.6 \quad 2645.6 \quad 2775.6
\end{array} \\
& (n=18) \quad(n=19) \quad(n=20)
\end{aligned}
$$

Figure 3. (a) MALDI-TOF mass spectrum of the PLLGA obtained from run 6 in Table 1, (b) the expanded spectrum, and (c) the structure and theoretical molecular weights.

To investigate the capability of the $\mathrm{P}_{2}-t-\mathrm{Bu}$ system, the ROP of L-MG was carried out using a range of initial monomer-to-initiator ratios ([L-MG $]_{0} /[\mathrm{PPA}]_{0}=100 / 1$ and $\left.200 / 1\right)$ to control the product molecular weight (runs 9 and 10 in Table 1, Figures S1i and S1j). The obtained PLLGAs showed $M_{\mathrm{n}, \mathrm{NMR}}$ values of 9.7 and $15.6 \mathrm{~kg} \mathrm{~mol}^{-1}$ with narrow $\Theta$ values of 1.22 and 1.29 , while retaining high $P$ values of 0.89 and 0.91 , respectively (Figures S13 and S14).

Given the well-controlled nature of the present ROP system, use of functional alcohol initiators instead of PPA should produce the highly alternating PLLAGs with various functional end groups (Scheme 1). Thus, the present ROP system was applied to the synthesis of PLLGA-diol as well as 
end-functionalized PLLGAs using 1,3-propanediol (PD), 6-azido-1-hexanol (AHA), 4-ethynylbenzyl alcohol (EBM), and poly(ethylene glycol) monomethyl ether (PEG-OH; $\left.M_{\mathrm{n}}=400 \mathrm{~g} \mathrm{~mol}^{-1}\right)($ runs $11-$ 14 in Table S1). Here, the PLLGA-diol serves as the prepolymer for a biocompatible/biodegradable polyurethane, ${ }^{34}$ and the PLLGAs prepared using AHA and EBM $\left(\mathrm{N}_{3}-\mathrm{PLLGA}\right.$ and HC$\equiv \mathrm{C}-\mathrm{PLLGA}$, respectively) could be applied for further functionalization through "click" reactions. ${ }^{35}$ Furthermore, PEG-PLLGAs could be of interest for biomedical materials analogous to the widely used PEGPLAs. ${ }^{36-38}$ Based on the ${ }^{1} \mathrm{H}$ NMR spectra of the obtained copolymers, signals derived from the corresponding initiator residues were observed, confirming the successful incorporation of the desired functionalities (Figures S15 and S16). Importantly, all PLLGAs exhibited narrow $Ð$ values of 1.121.33 and high $P$ values of $0.90-0.91$ (Figures S17-S20) regardless of the initiator used.

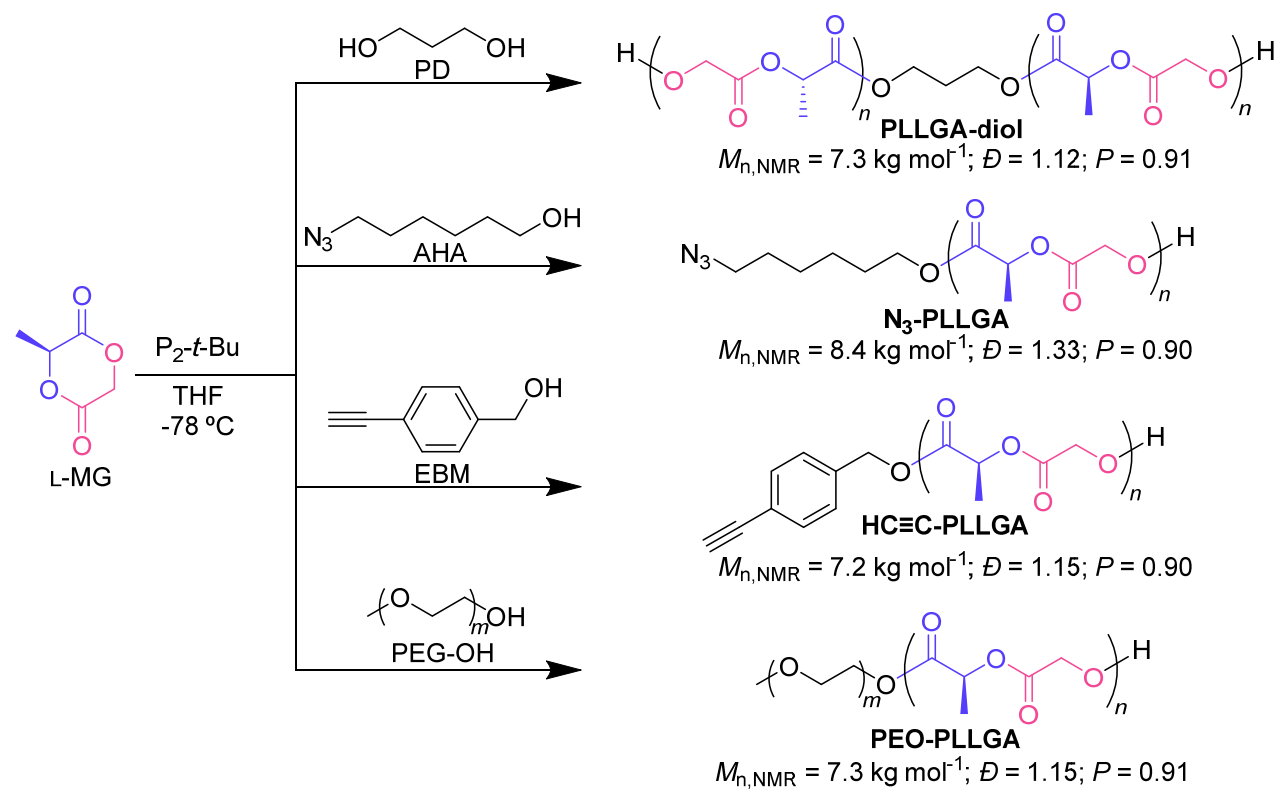

Scheme 1. $\mathrm{P}_{2}-t$-Bu-catalyzed ROP of L-MG using various initiators. 
To understand the regioselectivity during the ROP of L-MG using $\mathrm{P}_{2}-t$-Bu as the catalyst, we initially focused on the chain end structure of the copolymer. In the reported regioselective ROP systems of MG using organometallic catalysts, the chain ends of the resulting copolymers were mainly constituted of the lactyl group, implying that the organometal-catalyzed ROPs mainly proceed via glycolyl cleavage. ${ }^{15,16}$ In contrast, the ${ }^{1} \mathrm{H}$ NMR spectrum of the PLLGA obtained using $\mathrm{P}_{2}-t$-Bu as the catalyst (run 6 in Table 1) revealed a glycolyl-end/lactyl-end ratio of $0.73 / 0.27$, indicating that the majority of the chain end was constituted of the glycolyl group (Figure 4a). One might expect that the $P$ value should be comparable to the glycolyl-end/lactyl-end ratio. However, the end group ratio would be affected by not only the regioselectivity of the catalyst but also the relative reactivity (rate of consumption) between the two different end groups. Given the primary alcohol nature, the glycolyl-chain end should be consumed faster than the secondary alcohol lactyl-end. Consequently, a small amount of erroneously formed lactyl-end tends to survive than the glycolyl-end, which is why the apparent population of the lactyl-end was observed to be higher than $1-P$. The exceptionally fast polymerization of $\mathrm{MG}$ even at $-78^{\circ} \mathrm{C}$ seems to be correlated with the above-discussed polymerization pathway. For the ROP of LA, the propagation chain end is always a secondary alcohol, which render the whole polymerization reaction slower. ${ }^{22}$ On the other hand, the selective lactyl-cleavage of MG by the $\mathrm{P}_{2}-t-\mathrm{Bu}$-catalyzed ROP produces the propagating chain end mainly constituted of the primary alcohol, which is responsible for the faster polymerization of MG than LA despite the similar monomer structure. These results collectively suggest that the present ROP system mainly proceeds 
via lactyl cleavage (Figure 4d). 
(a)<smiles></smiles>

glycolyl-end/lactyl-end $=0.73 / 0.27$

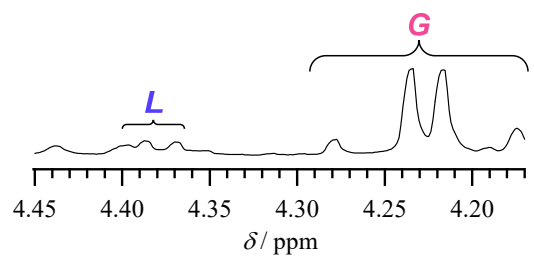

(b)

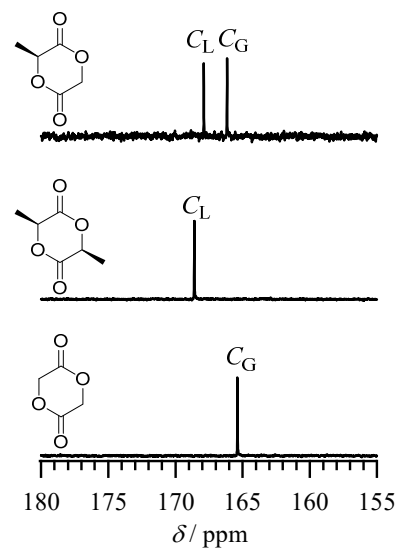

(c)

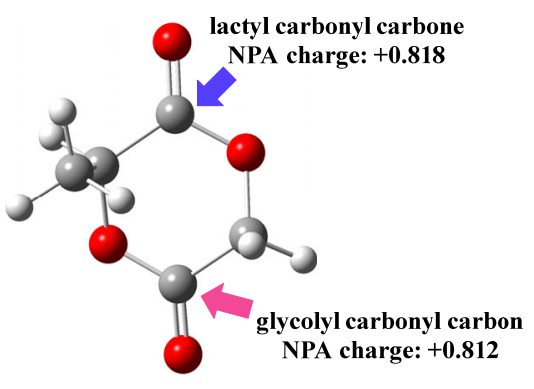

(d)

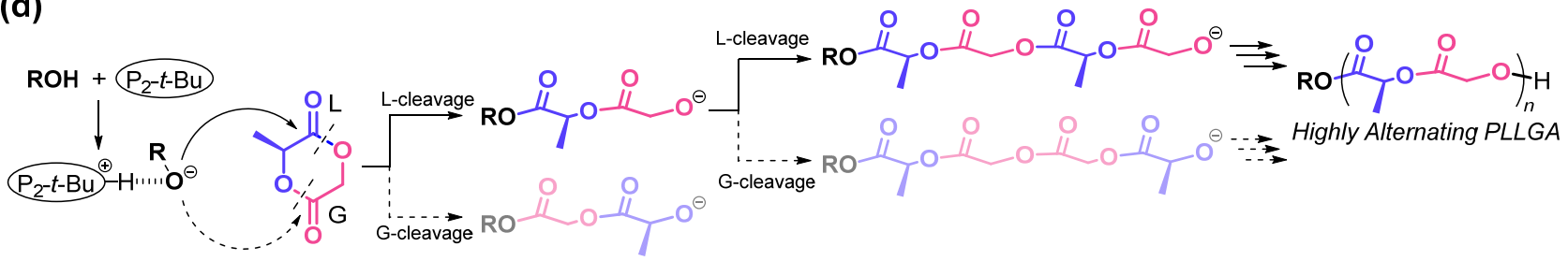

Figure 4. Investigation of the regioselectivity in the $\mathrm{P}_{2}-t$-Bu-catalyzed ROP of L-MG. (a) Partial ${ }^{1} \mathrm{H}$ NMR spectrum of the PLLGA obtained from run 6, Table 1 (in $\mathrm{CDCl}_{3} ; 400 \mathrm{MHz}$ ). (b) ${ }^{13} \mathrm{C} \mathrm{NMR}$ spectra of L-MG, L-LA, and GA (in DMSO- $d 6 ; 100 \mathrm{MHz}$ ). (c) NPA charge of the carbonyl carbon on the lactyl and glycolyl groups calculated at the $\mathrm{r} \omega \mathrm{B} 97 \mathrm{XD} / 6-31++\mathrm{g}(2 \mathrm{~d}, \mathrm{p})$ level of theory (CPCM in THF). The $\mathrm{C}, \mathrm{O}$, and $\mathrm{H}$ atoms are shown in gray, red, and white, respectively. (d) Expected polymerization pathway to produce highly alternating PLLGA.

To gain further insight into the unique regioselectivity of the present ROP system, we focused on the electron density of the carbonyl carbon. It was considered that the ${ }^{13} \mathrm{C}$ NMR chemical shift of the monomer carbonyl carbon should be a good measure of the electron density. ${ }^{39-41}$ The ${ }^{13} \mathrm{C}$ NMR analysis of L-MG, L-LA, and GA revealed that the electron density of the carbonyl carbon atom on the lactyl group $\left(C_{\mathrm{L}}\right)$ was lower than that of the glycolyl group $\left(C_{\mathrm{G}}\right)$ (Figure $\left.4 \mathbf{b}\right)$. In other words, $C_{\mathrm{L}}$ is more prone to nucleophilic attack than $C_{\mathrm{G}}$. This was further supported by natural population analysis (NPA) using density functional theory (DFT) calculations for L-MG (Figure 4c; see ESI for calculation details). Considering the anionic polymerization nature of the $\mathrm{P}_{2}-t$-Bu-catalyzed ROP 
(activated alcohol mechanism), ${ }^{42}$ the propagating oxyanionic species should preferentially attack the carbonyl carbon of the lactyl group, leading to selective ring-opening from the lactyl side. The key to the successful regioselective ROP seems to be the sufficient catalytic ability even at the low temperature enough to enhance the potential reactivity difference between the two ester groups in the cross dimeric monomer. One might expect that the bulky structure of the $\mathrm{P}_{2}-t$-Bu catalyst contributed to enhance the regioselectivity, as such the stereoselective ROP of $r a c$-LA using $\mathrm{P}_{2}-t$-Bu. ${ }^{22}$ However, the fact that less bulky TBD and MTBD also produced the highly alternating PLGAs indicates no significant impact of the catalyst bulkiness on the regioselectivity.

With the highly alternating PLGAs in hand, we finally investigated the impact of the alternating sequence on the stereocomplexation ability of the enantiomeric blends. According to the reported procedure, an enantiomeric 1:1 blend with a higher alternating sequence (Blend- $\left.\mathrm{P}_{2}-t-\mathrm{Bu}\right)$ was prepared by dissolving the PLLGA (run 6 in Table 1) and PDLGA (run 8, Table 1) in $\mathrm{CH}_{2} \mathrm{Cl}_{2}$ and subsequent solvent removal. ${ }^{10}$ For comparison purposes, PLLGA and PDLGA synthesized using DMAP (PLLGA: run 1; PDLGA: run 2 in Table 1) were also employed to prepare a further enantiomeric 1:1 blend with a less alternating sequence (Blend-DMAP). Although the PLLGA homopolymer (run 6) is amorphous (upper panel, Figure S21), the wide-angle X-ray diffraction (WAXD) profile of the Blend- $\mathrm{P}_{2}-t-\mathrm{Bu}$ exhibited three distinct diffraction peaks, suggesting crystallization upon blending (upper panel, Figure 5). Through comparison with the reported X-ray data, the diffraction peaks at $2 \theta(\lambda=1.50 \AA)$ of $16.9^{\circ}$ (interplanar distance $\left.(d)=10.2 \AA\right), 18.0^{\circ}(d=$ 
9.6 $\AA$ ), and $20.7^{\circ}(d=8.4 \AA)$ were assigned to the SC crystal. ${ }^{10}$ A similar WAXD profile was observed for the Blend-DMAP sample, but the diffraction peak intensities were lower than those observed for Blend- $\mathrm{P}_{2}-t-\mathrm{Bu}$ (lower panel, Figure 5a). Furthermore, the crystallinity $\left(X_{\mathrm{c}}\right)$ value for Blend- $\mathrm{P}_{2}-t-\mathrm{Bu}$ was estimated to be $24 \%$ from the WAXD profile (Figure S22), which is indeed significantly higher than the $X_{\mathrm{c}}$ value of 5\% for the Blend-DMAP sample (Figure S23). Differential scanning calorimetry (DSC) analysis also supported the X-ray diffraction results. More specifically, the DSC thermogram of Blend- $\mathrm{P}_{2}-t$-Bu exhibited a glass transition temperature $\left(T_{\mathrm{g}}\right)$ of $47.5{ }^{\circ} \mathrm{C}$, together with a melting temperature $\left(T_{\mathrm{m}, \mathrm{SC}}\right)$ of $182.5^{\circ} \mathrm{C}($ Figure $5 \mathbf{b})$. Importantly, the observed $T_{\mathrm{m}, \mathrm{SC}}$ value is closely matched with the reported value $\left(188^{\circ} \mathrm{C}\right),{ }^{10}$ which again confirms SC formation in the enantiomeric Blend$\mathrm{P}_{2}-t$-Bu. Furthermore, the observed $X_{\mathrm{c}}(24 \%)$ and melting enthalpy values for the SC $\left(\Delta H_{\mathrm{m}, \mathrm{SC}}=54.4\right.$ $\mathrm{J} \mathrm{g}^{-1}$ ) were in good agreement with the reported values for the blend of perfectly alternating PLGAs $\left(X_{\mathrm{c}}=20.8 \%, \Delta H_{\mathrm{m}, \mathrm{SC}}=53.4 \mathrm{~J} \mathrm{~g}^{-1}\right) .{ }^{10}$ This implies a nearly perfect alternating monomer sequence in the PLGAs obtained using $\mathrm{P}_{2}-t-\mathrm{Bu}$. Note that the small endothermic peak observed at $87.5{ }^{\circ} \mathrm{C}$ is attributable to the melting transition of the homochiral crystal $\left(T_{\mathrm{m}, \mathrm{HC}}\right)$. In clear contrast, in the case of Blend-DMAP, a $T_{\mathrm{m}, \mathrm{SC}}$ was observed with a negligibly small $\Delta H_{\mathrm{m}, \mathrm{SC}}$ value of $0.8 \mathrm{~J} \mathrm{~g}^{-1}$. To understand this significant difference, we calculated the probability of finding a perfect alternating sequence from a randomly selected $n$-mer based on the $P$ values of 0.95 for $\mathrm{P}_{2}-t$ - $\mathrm{Bu}$ and 0.69 for DMAP. As shown in Figure S24, only $16 \%$ of a perfect alternating sequence could be found from a randomly selected 10-mer for a copolymer with $P=0.69$, while $>77 \%$ of a perfect alternating sequence could be found 
where $P=0.95$. This clearly demonstrates that the negligible SC formation in the Blend-DMAP sample is attributed to the coexistence of numerous irregular monomer sequences.

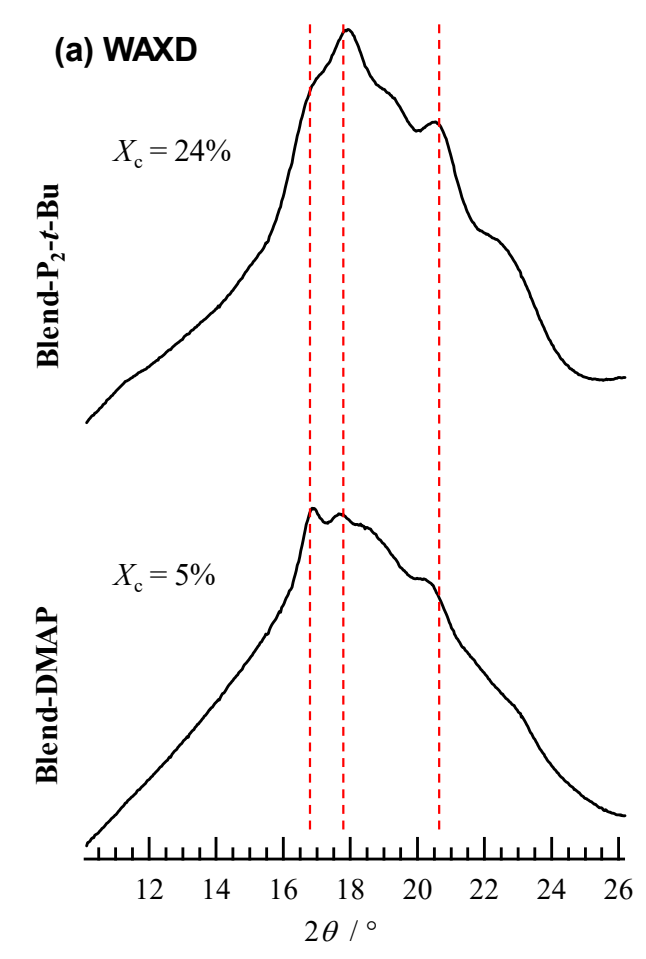

(b) DSC

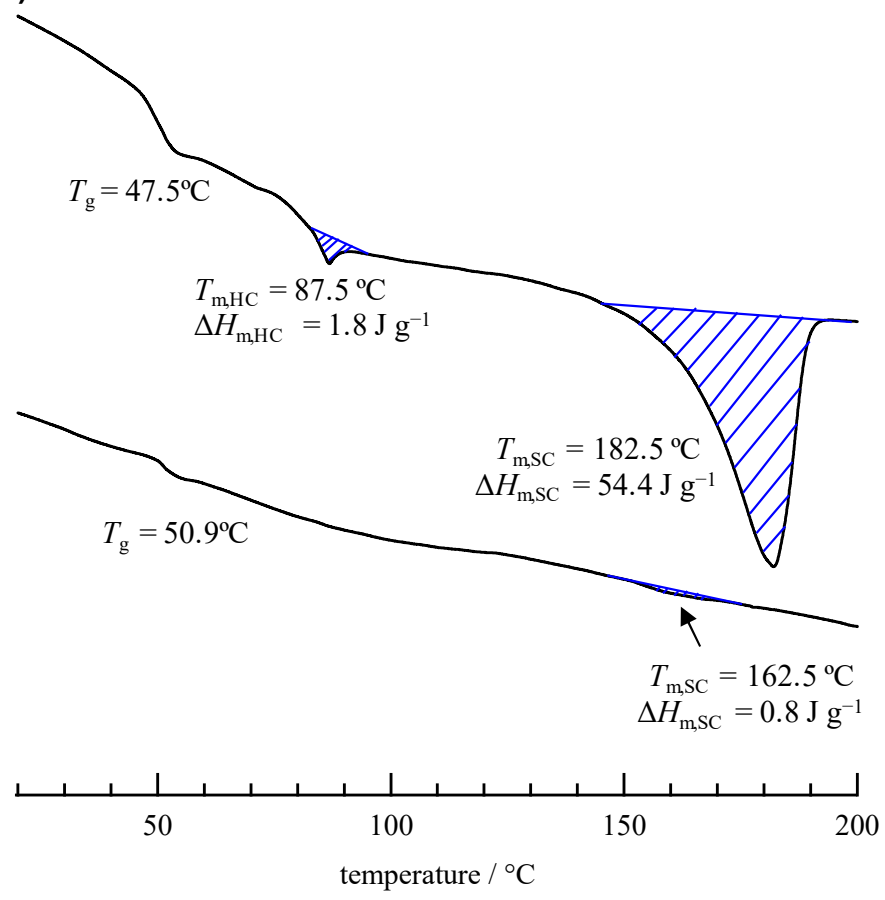

Figure 5. (a) WAXD profiles $(\lambda=1.50 \AA)$ and (b) $1^{\text {st }}$ heating DSC thermograms (heating rate, $10{ }^{\circ} \mathrm{C}$ $\mathrm{min}^{-1}$ ) of the 1:1 blend samples of PLLDA and PDLGA obtained using $\mathrm{P}_{2}-t$-Bu (Blend- $\mathrm{P}_{2}-t$-Bu; upper panel) and DMAP (Blend-DMAP; lower panel).

\section{Conclusion}

In summary, we successfully established a highly regioselective ring-opening polymerization (ROP) system for optically active methylglycolides (L- and D-MG) using phosphazene base $\mathrm{P}_{2}-t$ - $\mathrm{Bu}$ as the catalyst to afford highly alternating poly(lactic-co-glycolic acid)s (PLLGA and PDLGA) with controlled polymerization properties. Indeed, a $P$ value (probability of 
the ring-opening from the lactyl side) of 0.95 was achieved using this system, which is the highest value among the reported ROP systems for MG, and such an excellent selectivity has rarely been achieved by organocatalytic polymerization processes. Meanwhile, the ROP using bis(4-nitrophenyl) phosphate proceeded in a controlled manner but resulted in PLGA with random monomer sequence $(P=0.50)$. Given the good control over the polymerization process, in addition to the desirable regioselectivity and the metal-free nature, the organocatalytic ROP system is highly promising for application as a robust and versatile route to sequentially and structurally well-defined PLGAs for use in future biomedical applications. 
Electronic supplementary information (ESI) available. See DOI: XXX

Experimental details, homodecoupling ${ }^{1} \mathrm{H}$ NMR, SEC, MALDI-TOF MS, WAXD, and DSC data.

\section{Conflicts of interest}

There are no conflicts to declare.

\section{Acknowledgements}

This work was financially supported by the JSPS KAKENHI (Grant Number 20H04798, Hybrid Catalysis for Enabling Molecular Synthesis on Demand), Creative Research Institute (CRIS, Hokkaido University), and Photo-exitonics Project (Hokkaido University). T. Saito gratefully acknowledges the JSPS Fellowship for Young Scientists. 


\section{References and Note}

(1) K. Derakhshandeh, M. Erfan, and S. Dadashzadeh, Eur. J. Pharm. Biopharm., 2007, 66, 34 41.

(2) C. Fonseca, S. Simões, and R. Gaspar, J. Control. Release, 2002, 83, 273-286.

(3) L. Mu and S. S. Feng, J. Control. Release, 2003, 86, 33-48.

(4) P. Gentile, V. Chiono, I. Carmagnola, and P. V. Hatton, Int. J. Mol. Sci., 2014, 15, 3640-3659.

(5) J. Tiainen, Y. Soini, P. Törmälä, T. Waris, and N. Ashammakhi, J. Biomed. Mater. Res. - Part B Appl. Biomater., 2004, 70, 49-55.

(6) B. D. Ulery, L. S. Nair, and C. T. Laurencin, J. Polym. Sci. Part B Polym. Phys., 2011, 49, 832-864.

(7) O. Dechy-Cabaret, B. Martin-Vaca, and D. Bourissou, Chem. Rev., 2004, 104, 6147-6176.

(8) J. Li, S. N. Rothstein, S. R.Little, H. M. Edenborn, and T. Y. Meyer, J. Am. Chem. Soc., 2012, 134, 16352-16359.

(9) J. Li, R. M. Stayshich, and T. Y. Meyer, J. Am. Chem. Soc., 2011, 133, 6910-6913.

(10) H. Tsuji, M. Yamasaki, and Y. Arakawa, ACS Appl. Polym. Mater., 2019, 1, 1476-1484.

(11) N. W. Rebert, Macromolecules, 1994, 27, 5533-5535.

(12) R. M. Stayshich and T. Y. Meyer, J. Am. Chem. Soc., 2010, 132, 10920-10934.

(13) R. M. Stayshich, and T. Y. Meyer, J. Polym. Sci. Part A Polym. Chem., 2008, 46, 4704-4711.

(14) F.-R. Zheng, Y. Liang, and Z.-L Li, Molecules, 2018, 23, 452. 
(15) C. M. Dong, K. Y. Qiu, Z. W. Gu, and X.-D. Feng, J. Polym. Sci. Part A Polym. Chem., 2000, 38, 4179-4184.

(16) C. M. Dong, K. Y. Qiu, Z. W. Gu, and X.-D. Feng, J. Polym. Sci. Part A Polym. Chem., 2001, 39, 357-367.

(17) N. E. Kamber, W. Jeong, R. M. Waymouth, R. C. Pratt, B. G. G. Lohmeijer, and J. L. Hedrick, Chem. Rev., 2007, 107, 5813-5840.

(18) M. K. Kiesewetter, E. J. Shin, J. L. Hedrick, and R. W. Waymouth, Macromolecules, 2010, 43, 2093-2107.

(19) S. Hu, J. Zhao, G. Zhang, and H. Schlaad, Prog. Polym. Sci., 2017, 74, 34-77.

(20) G. Hua, J. Franzén, and K. Odelius, Macromolecules, 2019, 52, 2681-2690.

(21) A. P. Dove, H. Li, R. C. Pratt, B. G. G. Lohmeijer, D. A. Culkin, R. M. Waymouth, and J. L. Hedrick, Chem. Commun., 2006, 27, 2881-2883.

(22) L. Zhang, F. Nederberg, J. M. Messman, R. C. Pratt, J. L. Hedrick, and C. G. Wade, J. Am. Chem. Soc., 2007, 129, 12610-12611.

(23) G. M. Miyake and E. Y. X. Chen, Macromolecules, 2011, 44, 4116-4124.

(24) K. Makiguchi, T. Yamanaka, T. Kakuchi, M. Terada, and T. Satoh, Chem. Commun., 2014, 50, 2883-2885.

(25) J. B. Zhu and E. Y. X. Chen, J. Am. Chem. Soc., 2015, 137, 12506-12509.

(26) A. Sanchez-Sanchez, I. Rivilla, M. Agirre, A. Basterretxea, A. Etxeberria, A. Veloso, H. 
Sardon, D. Mecerreyes, and F. P. Cossío, J. Am. Chem. Soc., 2017, 139, 4805-4814.

(27) S. Liu, H. Li, N. Zhao, Z. Li, ACS Macro Lett., 2018, 7, 624-628.

(28) B. Orhan, M. J. L. Tschan, A. L. Wirotius, A. P. Dove, O. Coulembier, and D. Taton, ACS Macro Lett., 2018, 7, 1413-1419.

(29) Y. Tao, M. Li, Y. Tao, J. Tang, Y. Wang, X. Zhang, and X. Wang, J. Am. Chem. Soc., 2019, 141, 281-289.

(30) F. Nederberg, E. F. Connor, T. Glausser, and J. L. Hedrick, Chem. Commun., 2001, 20, 20662067.

(31) F. Nederberg, E. F. Connor, M. Möller, T. Glauser, and J. L. Hedrick, Angew. Chem. Int. Ed. Engl., 2001, 40, 2712-2715.

(32) N. Mase, Moniruzzaman; S. Yamamoto, K. Sato, T. Narumi, H. and Yanai, Tetrahedron Lett., 2019, 60, 150987.

(33) Note that the higher monomer conversion value for run 8 compared to run 6 does not represent the potential reactivity difference between D- and L-MGs. Since the polymerization is extremely fast, the monomer conversion increases significantly upon a slight delay of the termination reaction.

(34) A. K. Blakney, F. I. Simonovsky, I. T. Suydam, B. D. Ratner, and K. A. Woodrow, ACS Biomater. Sci. Eng., 2016, 2, 1595-1607.

(35) K. Kempe, A. Krieg, C. R. Becer, and U. S. Schubert, Chem. Soc. Rev., 2012, 41, 176-191. 
(36) R. Z. Xiao, Z. W. Zeng, G. L. Zhou, J. J. Wang, F. Z. Li, and A. M. Wang, Int. J. Nanomedicine, $2010,5,1057-1065$.

(37) J. D. Kretlow, L. Klouda, and A. G. Mikos, Adv. Drug Deliv. Rev., 2007, 59, 263-273.

(38) K. Zhang, X. Tang, J. Zhang, W. Lu, X. Lin, Y. Zhang, B. Tian, H. Yang, and H. He, J. Control. Release, 2014, 183, 77-86.

(39) H. Neuvonen and K. Neuvonen, J. Chem. Soc. Perkin Trans. 2, 1999, 7, 1497-1502.

(40) T. Ishizone, A. Hirao, and S. Nakahama, Macromolecules, 1993, 26, 6964-6975.

(41) T. Suzuki, J. I. Kusakabe, K. Kitazawa, T. Nakagawa, S. Kawauchi, and T. Ishizone, Macromolecules, 2010, 43, 107-116.

(42) L. Zhang, F. Nederberg, R. C. Pratt, R. M. Waymouth, J. L. Hedrick, and C. G. Wade, Macromolecules, 2007, 40, 4154-4158. 
TOC Graphic

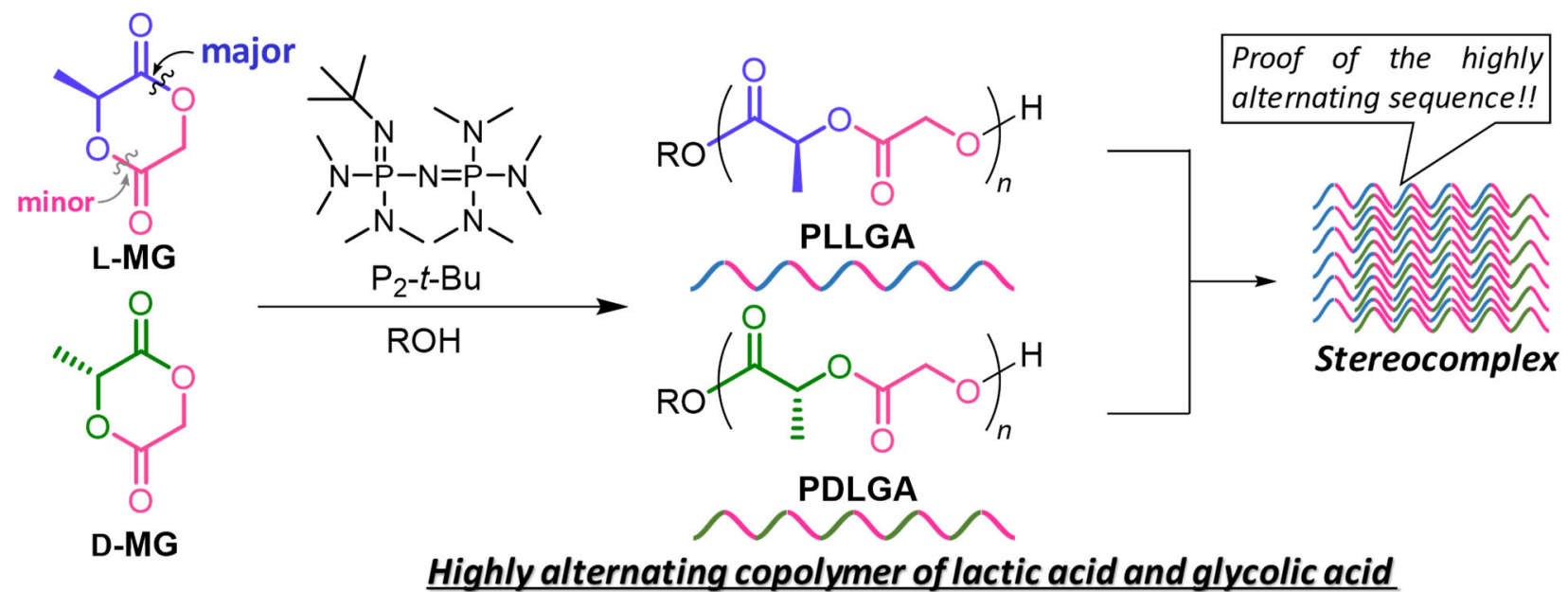

Highly alternating copolymer of lactic acid and glycolic acid

$\checkmark$ High regioselectivity $\quad \checkmark$ Metal free $\quad \checkmark$ Easy to control $M_{n}$ and end functionality $\quad \checkmark$ Narrow $\oplus$ 